\title{
DATA AKUNTANSI DALAM MEMPREDIKSI KEBANGKRUTAN: PERSPEKTIF HISTORIS DAN KONTEMPORER
}

\author{
SALIS MUSTA ANI \\ AMELIA OKTRIVINA SIREGAR \\ Universitas Pancasila, Jl. Raya Lenteng Agung No.56-80, RT.1/RW.3, Srengseng Sawah, Kec. Jagakarsa, \\ Jakarta 12640, Indonesia \\ salisaeffendy@gmail.com, ameliaoktrivina@univpancasila.ac.id
}

Abstract: This paper discusses the development of the use of accounting data in predicting corporate bankruptcy (financial distress) and the role of accounting data in predicting bankruptcy. Research completion will be divided into several developments, covering the 1930s until the 2000s.

Keywords: Financial distress, accounting data, bankruptcy, history

Abstrak: Artikel ini membahas pengembangan penggunaan data akuntansi dalam memprediksi kebangkrutan perusahaan (financial distress) dan peran data akuntansi dalam memprediksi kebangkrutan. Penyelesaian penelitian akan dibagi menjadi beberapa perkembangan, meliputi tahun 1930-an hingga 2000-an.

Kata kunci: Kesulitan keuangan, data akuntansi, kebangkrutan, historis

\section{PENDAHULUAN}

Sebuah perusahaan dalam menjalankan usahanya pasti menginginkan usahanya berlangsung lama dan dapat mencapai laba yang maksimal. Akan tetapi, dalam kenyataannya operasi perusahaan tidak selalu berjalan sesuai yang diinginkan dan mencapai hasil yang diharapkan. Tercatat dalam dekade ini, beberapa perusahaan besar di dunia mengalami collaps, bahkan ada yang kemudian bangkrut karena ketatnya persaingan di dunia industri. Kodak yang dulu selalu terdepan dalam persaingan industri film, kamera, dan percetakan, pada tahun 2012 harus mengajukan permohonan perlindungan kebangkrutan (koran-sindo.com edisi 10
Februari 2016). Demikian juga Blockbuster yang merupakan perusahaan penyewaan video dan DVD menutup 300 cabangnya dan mengajukan permohonan kebangkrutan, Selain itu, perusahaan radio dan alat-alat elektronik, RadioShack juga mengajukan permohonan kebangkrutan pada Februari 2015, padahal dulu perusahaan tersebut selalu memegang rekor penjualan tertinggi untuk $C D$ dan walkman (koran-sindo.com edisi 10 Februari 2016). Atari Inc pada tahun 2013 juga mengajukan kebangkrutan. Perusahaan yang pernah berjaya pada era 1970-an sampai 1980-an dalam pembuatan konsol video game itu mengalamai penurunan laba yang cukup mencolok pada tahun 2011 dan 2012 (koran-sindo.com edisi 10 Februari 2016). 
Beberapa perusahaan besar di Indonesia juga mengalami kebangkrutan pada dekade ini. General Motor Indonesia (GMI) resmi ditutup pada Juni 2015 karena selalu mengalami kerugian dan ketidakmampuan dalam persaingan dengan produk sejenis lain. Menyusul Ford Motor Indonesia pada awal tahun 2016, juga menutup bisnisnya di Indonesia (Koran-sindo edisi 10 Februari 2016). Beberapa perusahaan ini merupakan contoh bahwa berjalannya operasi perusahaan akan selalu dinamis, penuh dengan persaingan, dan tantangan untuk selalu berinovasi. Perusahaan yang bersifat statis dan tidak menciptakan inovasi, dan selanjutnya kalah bersaing maka perusahaan kemungkinan akan terus menurun kondisinya.

Jika perusahaan yang bangkrut merupakan perusahaan yang tidak terdapat tuntutan akuntabilitas di dalamnya, akan mengakibatkan kerugian di pihak internal. Akan tetapi, bagi perusahaan publik, hal ini tentu akan merugikan banyak pihak, seperti creditors, shareholder, pemerintah, dan stakeholder lain. Altman (1968) telah menemukan model (formula) untuk menangkap sinyal kebangkrutan yang dapat menjadi gambaran kondisi perusahaan beberapa tahun sebelum mengalami kebangkrutan. Formula ini menggunakan informasi akuntansi yang diungkapkan perusahaan setiap periode. Data akuntansi yang digunakan adalah working capital, total assets, retained earnings, earnings before interest and taxes, market value of equity, book value of total debt, dan sales (Watts and Zimmerman 1986, 115).

Setelah Altman (1968), banyak alternatif model untuk memprediksi kebangkrutan, antara lain Springate (1978) dalam Salahi dan Shiri (2016), Zmijewski (1984), Ohlson (1980), Deakin (1972). Altman juga telah memperbaharui formulanya melalui Altman (1977). Akan tetapi, sebenarnya penggunaan data akuntansi untuk memprediksi kondisi financial distress perusahaan sudah dirumuskan sejak tahun 1930-an (Bellovary et al. 2007).
Hampir setengah abad kajian tentang prediksi kebangkrutan perusahaan ini dilakukan. Tentu telah banyak pemikiran sejenis yang di-review, diberikan saran, serta kritik guna penyempurnaan rumusan lama. Penelitian ini mencoba menelusuri penggunaan data akuntansi dalam memprediksi kebangkrutan perusahaan dari waktu ke waktu. Tulisan ini diilhami oleh tulisan Wolk, Dodd, dan Rozycki $(2017,228)$ yang menyampaikan bahwa rasio berbasis data akuntansi sangat bermanfaat dalam memprediksi kebangkrutan.

$$
\text { Penelitian tentang prediksi }
$$

kebangkrutan ini telah banyak dilakukan dalam berbagai perspektif kajian. Khusus dalam perspektif penelusuran berbentuk review literatur, telah dilakukan oleh Bellovary, Giacomino, dan Akers (2007), Beaver, Correia, McNichols (2010), Sun dkk. (2014), Appiah et al. (2015), serta Abdullah dan Malik (2017). Akan tetapi, penelitian tersebut lebih membahas prediksi kebangkrutan secara global dan tidak fokus pada data akuntansi yang digunakan. Penelitian ini lebih menekankan pada data-data akuntansi yang digunakan oleh para peneliti seperti Beaver (1966), Altman (1968), Zmijweski (1984), dan lainnya.

Penelitian ini akan menelusuri berbagai kajian yang menggunakan data-data akuntansi dalam memprediksi kebangkrutan perusahaan dari waktu ke waktu. Apakah penggunaan model prediksi tahun 1960-an masih relevan hingga saat ini? Akan dikaji pula sejauh mana data-data akuntansi tersebut berperan dalam memprediksi kebangkrutan. Tujuan penelitian adalah untuk melihat perkembangan penggunaan data-data akuntansi dalam memprediksi kebangkrutan dan data-data akuntansi apa saja yang digunakan dalam memprediksi kebangkrutan selama ini. Penelitian ini juga dapat bermanfaat bagi praktisi dalam menentukan formula prediksi kebangkrutan mana yang masih relevan dan banyak digunakan. 


\section{Financial Distress}

Financial distress menurut Beaver, Correia, dan Nichols (2010) adalah ketidakmampuan perusahaan untuk membayar kewajiban keuangannya pada saat jatuh tempo. Dalam kajian empiris di bidang akuntansi dan finance, hal ini sering dikaitkan dengan bond default atau bankruptcy. Financial distress dapat juga didefinisikan sebagai sebuah proses yang dilakukan berdasarkan undang-undang kepailitan saat perusahaan tidak mampu membayar atau mencapai kesepakatan dengan kreditur di luar pengadilan (Watss dan Zimmerman 1986, 112).

Ross et al. $(2005,830)$ mendefinisikan financial distress sebagai suatu kondisi di mana cash flow operasi perusahaan tidak mencukupi untuk memenuhi kewajibannya dan perusahaan terpaksa mengambil tindakan korektif. Definisi ini lebih jelas menunjukkan letak data akuntansi yang merupakan sumber pokok dari kondisi ini. Mereka juga menghubungkan financial distress dengan insolvency yang mencakup dua tema umum, yaitu stocks dan flows. Insolvency berbasis stocks terjadi jika kekayaan bersih perusahaan bernilai negatif, selain itu nilai aset kurang dari nilai hutangnya, sedangkan insolvency berbasis flow terjadi saat perusahaan tidak mampu dalam membayar hutanghutangnya. Altman (1993) merupakan salah satu yang pertama membedakan kedua kategori insolvency tersebut (Ross et al. 2005, 831).

Perusahaan yang akan mengalami kebangkrutan, biasanya akan menunjukkan gejala tertentu yang merupakan sinyal akan datangnya kebangkrutan, salah satunya pada tahun-tahun terakhir (kurang lebih tiga tahun terakhir) perusahaan mempunyai saldo laba negatif (IAI 2004). Selain itu, gejala lain yang mungkin terlihat adalah pengurangan jumlah dividen, penutupan beberapa tempat operasi, pemutusan hubungan kerja, pengunduran diri CEO, serta merosotnya harga saham (Ross et al. 2005, 830). Oleh karena itu, penting untuk melakukan prediksi kebangkrutan (Hwang et al. 2013). Dalam beberapa penelitian, beberapa peneliti memilih perusahaan dengan kategori financial distress sebagai sampel, yaitu perusahaan yang mempunyai negative working capital, negative retained earnings, atau bottom line loss (Feldman dan Read 2013; Foster dan Zurada 2013).

Penelitian tentang prediksi financial distress perusahaan masih menarik untuk dikaji hingga kini. Topik tersebut selalu up to date untuk dibahas meskipun telah diulas sejak setengah abad lalu. Hal ini karena berjalannya operasi perusahaan penuh dinamika dan bisa sewaktu-waktu berhadapan dengan ketidakpastian lingkungan, percepatan teknologi, dan kompetisi yang sangat ketat.

Beaver et al. (2010) melakukan review literature dan kajian konseptual dalam financial distress. Appiah, Chizema, Arthur (2015) menelusuri literatur financial distress dengan penekanan metodologi yang digunakan para peneliti. Bellovary, Giacomino, dan Akers (2007), juga melakukan review literature untuk melihat gambaran perkembangan metodologi yang digunakan untuk mengungkapkan perusahaan yang mengalami kegagalan dalam usahanya.

Sun dkk. (2014), melakukan review tentang prediksi financial distress yang bersifat menyeluruh terkait definisi, modeling, sampling, dan juga featuring. Abdullah dan Malik (2017). juga me-review penelitian terkait financial distress ini. Dari semua review yang pernah dilakukan, sangat jarang review yang hanya membahas data akuntansi yang digunakan dalam prediksi. Dalam paper ini difokuskan hanya pada data-data akuntansi yang digunakan.

\section{METODA}

Penelitian ini merupakan kajian literatur yang menelusuri tulisan-tulisan mengenai prediksi kebangkrutan perusahaan atau kondisi financial distress dari waktu ke waktu, sejak penelitian awal pada tahun 1930-an hingga periode terkini. Fokus lebih ditekankan pada 
peran data-data akuntansi yang digunakan peneliti dalam memprediksi kebangkrutan. Jadi, penelitian ini tidak mencakup metodologi penelitian yang di-review.

\section{HASIL DAN PEMBAHASAN}

\section{Informasi Akuntansi dan Manfaatnya bagi Investor dan Kreditur}

Informasi akuntansi telah banyak dimanfaatkan oleh banyak pengguna dalam pengambilan keputusan, terutama pengguna utama, yaitu creditor dan shareholder. Data akuntansi yang telah digunakan adalah earnings, dividen, dan stock prices dalam valuation, serta residual income. Selain itu, datadata akuntansi terkait penghitungan risk dan return pada teori EMH dan CAPM juga digunakan. Kandungan data dalam cash flow juga merupakan informasi yang bermanfaat bagi pengguna, kemudian juga firm's pension plant assets dan liabilities, research and development ( $R$ and D) expenditures (Wolk et al. 2017).

Selain bermanfaat dalam pengambilan keputusan, data-data akuntansi juga dapat digunakan untuk memprediksi kondisi keuangan perusahaan di masa yang akan datang, seperti prediksi kebangkrutan perusahaan pada beberapa tahun kemudian. Watts and Zimmerman (1986) menyebutkan bahwa datadata akuntansi sangat berperan dalam memprediksi kebangkrutan. Menurut mereka, salah satu alasan digunakannya data akuntansi dalam hal ini adalah karena dalam bond indentures dan lending agreeements sering menggunakan rasio akuntansi untuk membatasi tindakan manajer. Dicontohkan oleh Watts and Zimmerman (1986) bahwa manajer mungkin diminta untuk mempertahankan current ratio yang minimal. Akan tetapi, jika terjadi pelanggaran, hal tersebut merupakan wan prestasi yang kemudian dapat menyebabkan perusahaan mengalami kebangkrutan. Memang tidak selalu setiap terjadi pelanggaran perjanjian dengan memasukkan rasio akuntansi di dalamnya akan mengakibatkan kebangkrutan.
Oleh karena itu, Watts and Zimmerman (1986) menegaskan bahwa tidak terdapat hubungan mekanis antara rasio akuntansi dan kebangkrutan karena default didefinisikan menggunakan rasio tersebut. Namun demikian, penggunaan data akuntansi dapat merupakan sinyal kegagalan dan memberikan debtholders pilihan untuk menekan kebangkrutan yang menunjukkan bahwa angka-angka dan rasio tersebut berhubungan dengan nilai perusahaan dan nilai nominal hutang.

\section{Prediksi Financial Distress dengan Data Akuntansi}

a. Periode 1930-an

Studi awal tentang kebangkrutan perusahaan diterbitkan pada tahun 1930-an dan 1940-an setelah terjadi depresi dan banyaknya perusahaan yang collapsed. Pada tahun-tahun tersebut mulai disadari bahwa prediksi kebangkrutan cukup penting (Amendola, dkk., 2011). Smith (1930) dalam Amendola, dkk. (2011) memelopori kajian dengan analisis rasio dari 29 perusahaan yang gagal selama tahun 1920-an. Rasio yang digunakan antara lain net earnings to total assets; net income to net worth; working capital and fixed assets to total assets; current ratio).

Fitzpatrick (1931, 1932) dalam Amendola, dkk. (2011) mencoba menganalisis kegagalan dua puluh perusahaan pada tahun 1920 melalui penghitungan tiga belas rasio. Sementara itu, pada studi yang lain dia mencoba membandingkan 20 perusahaan yang sama dengan perusahaan berkembang lainnya. Hasil penelitiannya menunjukkan bahwa analisis rasio dapat menjadi alat yang berguna untuk melihat perusahaan yang sukses dan gagal.

\section{b. Periode 1960-an}

Beaver (1966) memelopori kajian pada periode ini. Beaver (1966) menghitung rasio dengan kriteria, yaitu tingkat kepopuleran rasio tersebut, rasio memiliki kinerja baik pada studi sebelumnya, dan rasio tersebut dapat didefinisikan dalam bentuk konsep arus kas. 
Berikut ini beberapa rasio yang digunakan Beaver (1966), yaitu: cash flow/total debt; net income/total assets; total debt/total assets; nworking capital/total assets; debt ratio, and nocredit interval. Hasil penelitian Beaver (1966) adalah bahwa rasio keuangan perusahaan yang gagal berbeda dari berusahaan yang tidak gagal.

Selain Beaver (1966), terdapat prediksi kebangkrutan Altman (1968) yang dikenal dengan Altman's ZETA yang telah banyak digunakan oleh perusahaan-perusahaan (Kuruppu et al. 2003). Z-score model ini dipandang lebih akurat karena menggunakan kombinasi analisis rasio dengan pendekatan statistic MDA (multivariate discriminant analysis) (Amendola et al. 2011). Ide Altman (1968) ini hingga kini masih merupakan predictor yang sangat kuat dan mengilhami peneliti sejenis lain pada beberapa dekade berikutnya. Altman (1968) menggunakan rasio data akuntansi berupa: working capital/total assets, retained earnings/ total assets, earnings before interest and taxes/ total assets, market value of equity/ book value of total debt, dan sales/ total assets.

\section{c. Periode 1970 -an}

Altman (1968) merevisi model yang digunakannya dan dirumuskan dalam formula sejenis pada tahun 1977 bersama peneliti lain, yaitu Haldeman dan Narayanan. Pada periode ini muncul juga Deakin (1970) dalam LeClere (2006) menggunakan rasio cash/current debts, cash/sales, cash/total assets, cash flow/total debts, current assets/current debts, current assets/sales, current assets/total assets, net income/total assets, quick assets/current debts, quick assets/sales, quick assets/total assets, total debts/total assets, working capital/sales. Salahi dan Shiri (2016) melanjutkan studi Altman dengan rasio sebagai berikut: dependent variables of current assets to total assets, preprofit and tax to total assets, pre-tax profit to current liability and sales to total assets,

\section{d. Periode 1980-an}

Ohlson (1980) meneliti prediksi financial distress melalui pengujian rasio, yaitu: change in income/sum of the absolute value of net income for two years, current debts/current assets, log (total assets/GNP price level index), net income/total assets, owners' equity (positive or negative), positive or negative earnings, dan total debts/total assets.

Taffler (1982) dalam Agrawal and Taffler (2003) menggunakan EBIT/total assets; total liabilities/capital employed; quick assets/ total assets; working capital/net worth stockturn. Zaygren (1983) dalam Cultera dan Bredart (2016) menguji rasio inventory/sales; amounts receivable/inventory; (cash _ $\quad$ ST investment)/total assets; quick ratio; net return on equity after taxes; sales/total assets; (liabilities-accrued charges and deferred income)/equity dalam memprediksi financial distress.

\section{e. Periode 1990-an}

Model prediksi kebangkrutan tradisional tahun 60-an, 70-an dan 80-an belum sepenuhnya memuaskan (Cybinski 2001). Oleh karena itu, banyak peneliti masih mengkaji model yang tepat untuk prediksi kebangkrutan. Plat dan Plat (1990) dalam Cultera dan Bredart (2016) meneliti penggunaan sales growth; cash flow/sales; net fixed/total assets; total debt/total assets; ST debt/total debt; (output _ cash flow)/sales; (output_total debt)/total assets. Pada periode ini juga terdapat peneliti financial distress lainnya, yaitu Hopwood (1994). Model yang digunakan yaitu menggunakan data akuntansi yang terdiri dari net income, total assets, current assets, current liabilities, long term debt, dan log of total sales.

\section{f. Periode 2000-an}

Pada periode ini, Shumway (2001) dalam Foster (2013) menyebutkan bahwa terdapat metode yang berpotensi lebih kuat dibandingkan model berbasis akuntansi tradisional dalam mengevaluasi risiko kebangkrutan, yaitu hazard model. Metode ini 
mempunyai keunggulan dibandingkan dengan model statis. Model ini secara otomatis menyesuaikan tahun-tahun risiko sebelum perusahaan bangkrut. Selain itu, model ini memungkinkan penggunaana lebih banyak informasi (pengamatan) karena perusahaan dianggap sebagai pengamatan terpisah. Namun demikian, model ini perlu menghasilkan perkiraan parameter yang lebih tepat dan perkiraan out-of-sample yang lebih baik. Penelitian Shumway (2001) dalam Foster (2013) menggunakan data akuntansi sebagai berikut: total liabilities/total assets, relative size based on market value, dan stock return over year prior to bankruptcy relative to market return.
Charitou et al. (2000) dalam Appiah dan Abor (2009) menyimpulkan bahwa rasio laba ditahan terhadap total asset mempunyai kemampuan untuk memprediksi kegagalan dalam dua tahun sebelum terjadi kebangkrutan. Beaver et al. (2005) menggunakan data akuntansi tiga model variabel, yaitu: 1) earnings before interest/ total assets, 2) net income before interest, taxes, depreciation, depletion, dan amortisasil total liabilities, 3) total liabilities/total assets. Berikut ini merupakan tabel data akuntansi berdasarkan periode tahun penelitian:

Tabel 1 Data Akuntansi yang Digunakan dalam Model Prediksi Financial Distress

\begin{tabular}{|c|c|c|}
\hline Nomor & Peneliti & $\begin{array}{l}\text { Data Akuntansi yang } \\
\text { Digunakan dalam Memprediksi } \\
\text { Financial Distress }\end{array}$ \\
\hline & Tahun 1960-an & \\
\hline 1 & Beaver (1966) & $\begin{array}{l}\text { Cash flow/total debt; net } \\
\text { income/total assets; total } \\
\text { debt/total assets; } \\
\text { working capital/total assets; debt } \\
\text { ratio and no-credit interval }\end{array}$ \\
\hline \multirow[t]{6}{*}{2} & Altman (1968) & $\begin{array}{ll}\text { a. Working capital/total assets } \\
\\
\text { (X1) } \\
\text { b. Retained earnings/total } \\
\text { assets (X2) }\end{array}$ \\
\hline & & $\begin{array}{l}\text { c. Earnings before interest and } \\
\text { taxes/total assets (X3) }\end{array}$ \\
\hline & & $\begin{array}{l}\text { d. Market value of equity/book } \\
\text { value of total debt (X4) }\end{array}$ \\
\hline & & e. Sales/total assets (X5) \\
\hline & & $\begin{array}{l}Z=1.2 \times 1+1,4 \times 2+3.3 \times 3+ \\
0.6 \times 4+1.0 \times 5\end{array}$ \\
\hline & Tahun 1970-an & \\
\hline 1 & Deakin (1972) dalam LeClere (2006) & $\begin{array}{l}\text { a. cash/current debts, } \\
\text { b. cash/sales, } \\
\text { c. cash/total assets, } \\
\text { d. cash flow/total debts, } \\
\text { e. current assets/current debts, } \\
\text { f. current assets/sales, }\end{array}$ \\
\hline
\end{tabular}




\begin{tabular}{|c|c|c|}
\hline Nomor & Peneliti & $\begin{array}{c}\text { Data Akuntansi yang } \\
\text { Digunakan dalam Memprediksi } \\
\text { Financial Distress }\end{array}$ \\
\hline 2 & $\begin{array}{l}\text { Springate (1978) dalam Salehi dan Shiri } \\
\text { (2016) }\end{array}$ & $\begin{array}{l}\text { g. current assets/total assets, } \\
\text { h. net income/total assets, } \\
\text { i. quick assets/current debts, } \\
\text { j. quick assets/sales, } \\
\text { k. quick assets/total assets, } \\
\text { I. total debts/total assets, } \\
\text { m. working capital/sales. } \\
\text { a. current assets to total } \\
\text { assets, } \\
\text { b. pre-profit and tax to total } \\
\text { assets, } \\
\text { c. pre-tax profit to current } \\
\text { liability } \\
\text { d. sales to total assets }\end{array}$ \\
\hline \multicolumn{3}{|c|}{ Tahun 1980-an } \\
\hline 2 & Altman (1983) revisi dari Altman (1968) & $\begin{array}{l}\text { a. change in income/sum of the } \\
\text { absolute value of net income } \\
\text { for two years, } \\
\text { b. current debts/current assets, } \\
\text { c. Iog (total assets/GNP price } \\
\text { level index), } \\
\text { d. net income/total assets, } \\
\text { e. owners' equity (positive or } \\
\text { negative), } \\
\text { f. positive or negative } \\
\text { earnings, } \\
\text { g. total debts/total assets. } \\
\text { x6 => net worth (book value)/ } \\
\text { total liabilities }\end{array}$ \\
\hline & & $\begin{array}{l}Z^{\prime}=0.717 X 1+0,847 \times 2+ \\
3,107 X 3+0,420 \times 6+0,998 \times 5\end{array}$ \\
\hline & & $\begin{array}{l}Z^{\prime \prime}=6,56 \times 1+3,26 \times 2+6,72 \times 3+ \\
105 \times 6\end{array}$ \\
\hline 3 & $\begin{array}{l}\text { Taffler (1982) dalam Agrawal and Taffler } \\
\text { (2003) }\end{array}$ & $\begin{array}{ll}\text { a. } & \text { EBIT/total assets; } \\
\text { b. } & \text { total liabilities/capital } \\
& \text { employed; } \\
\text { c. } & \text { quick assets/ total assets; } \\
\text { d. } & \text { working capital/net worth } \\
& \text { stockturn }\end{array}$ \\
\hline 4 & $\begin{array}{l}\text { Zaygren (1983) dalam Cultera dan Bredart } \\
\text { (2016). }\end{array}$ & a. inventory/sales; \\
\hline
\end{tabular}




\begin{tabular}{|c|c|c|}
\hline Nomor & Peneliti & $\begin{array}{c}\text { Data Akuntansi yang } \\
\text { Digunakan dalam Memprediksi } \\
\text { Financial Distress }\end{array}$ \\
\hline & & $\begin{array}{ll}\text { b. } & \text { amounts } \\
& \text { receivable/inventory; } \\
\text { c. } & \text { (cash_ST investment)/total } \\
& \text { assets; } \\
\text { d. } & \text { quick ratio; } \\
\text { e. } & \text { Net return on equity after } \\
& \text { taxes; } \\
\text { f. } & \text { sales/total assets; } \\
\text { g. } & \text { (liabilities-accrued charges } \\
& \text { and deferred income)/equity }\end{array}$ \\
\hline 5 & Zmijweski (1984) & $\begin{array}{l}\text { a. current cash, } \\
\text { b. performance } \\
\text { c. financial level of commercial } \\
\text { units }\end{array}$ \\
\hline & Tahun 1990-an & \\
\hline 1 & $\begin{array}{l}\text { Plat and Plat (1990) dalam Cultera dan } \\
\text { Bredart (2016) }\end{array}$ & $\begin{array}{l}\text { a.sales growth; } \\
\text { b.cash flow/sales; } \\
\text { c. net fixed/total assets; } \\
\text { d.total debt/total assets; } \\
\text { e.ST debt/total debt; } \\
\text { f. (output_cash flow)/sales; } \\
\text { g.(output_total debt)/total assets }\end{array}$ \\
\hline 2 & Hoopwood's Score (1994) & $\begin{array}{l}\text { Net income, total assets, current } \\
\text { assets, current liabilities, long } \\
\text { term debt, log of total sales. } \\
\left(-7.322+\left(-15.756^{*} \mathrm{NI} / \mathrm{TA}\right)+\right. \\
\left(0.973^{*} \mathrm{CA} / \text { Sales }\right)+(1.667 \\
\left.{ }^{*} \mathrm{CA} / \mathrm{CL}\right)+\left(5.985^{*} \mathrm{CA} / \mathrm{TA}\right)+(- \\
\left.9.145^{*} \text { Cash/TA }\right)+\left(4.224^{*} \mathrm{LTD} / \mathrm{TA}\right) \\
+\left(0.214^{*} \text { LnSales }\right)\end{array}$ \\
\hline & Tahun 2000-an & \\
\hline 1 & Amershi (2000) & $\begin{array}{l}\text { Total debt/ total invested capital } \\
\text { Golden Mean (GM) }\end{array}$ \\
\hline 2 & Grice dan Ingram (2001) & $\begin{array}{l}\text { Grice Model: } \\
\text { a. net profit of total assets } \\
\text { b. total liabilities to total assets }\end{array}$ \\
\hline 3 & Shumway (2001) dalam Foster (2013) & $\begin{array}{l}\text { a. Total liabilities/total assets } \\
\text { b. Relative size based on market } \\
\text { value } \\
\text { c. Stock return over year prior to } \\
\text { bankruptcy relative to market } \\
\text { return. }\end{array}$ \\
\hline
\end{tabular}




\section{PENUTUP}

Penggunaan data-data akuntansi dalam memprediksi kebangkrutan dari waktu ke waktu menunjukkan bahwa data akuntansi tersebut sangat berperan. Pada tahun 1930-an telah digunakan rasio dalam memprediksi kebangkrutan. Pengujian lebih berkembang lagi saat Beaver (1966) dan Altman (1968) memunculkan model prediksi kebangkrutan. Periode 1970-an, peneliti berusaha menyempurnakan formula/model yang ada, termasuk Altman (1977). Deakin (1972) menggunakan data-data akuntansi yang lebih lengkap dan representative. Ohlson (1980) menggunakan formula yang berbeda dan karyanya mengawali era 1980-an. Tahun 1990, terdapat peneliti Plat dan Plat (1990) dalam Cultera dan Bredart (2016) dan Hopwood (1994). Era tahun 2000-an telah muncul berbagai peneliti dalam bidang sejenis dengan beragam metode terbaru, namun penggunaan metode Altman (1968) dan Beaver (1966) masih tetap menjadi acuan.

\section{REFERENSI:}

Abdullah, Nur Diyana dan Sulaiman Abdul Malik. 2017. "A Review of Business Failure Prediction Models Used on Financial Distressed Companies". Advanced Science Letters, 23(11), November.

Achim, Monica Violeta, Sorin Nicolae Borlea, dan Lucian Vasile Gaban. 2016. "Failure Prediction from The Investors' View by Using Financial Ratios. Lesson from Romania". E+M Ekonomie a Management, 19(4), ABI/INFORM Collection.

Altman, Edward I., 1968. "Financial Ratios, Discriminant Analysis and the Prediction of Corporate Bankruptcy". The Journal of Finance, 23(4). Sep,. 589-609.

Altman, Edward I., 1993. Corporate Financial Distress and Bankruptcy: A Complete Guide to Predicting and Avoiding Distress and Profiling from Bankruptcy, $2^{\text {nd }}$ ed., Willey, New York, NY.

Amershi, Amin H. 2000. "The Occurrence of Fibonacci Numbers in time Series of Financial Accounting Ratios: Anomalies or Indicators of Firm Survival, Bankrupty dan Fraud? An Exploratory Study". Managerial Finance, 26(11), 5-20.

Amendola, Alessandra, Marco Bisogno, Marialuisa Restaino, Luca Sensini, 2011 "Forecasting Corporate Bankruptcy: Empirical Evidence on Italian Data", EuroMed Journal of Business, 6(3),.294-312

Aminian, Abolfazi, Hedayat Mousazade, Omid Imani Khoshkho. 2016. "Investigate the Ability of Bankruptcy Prediction Models of Altman and Springate and Zmijewski and Grover in Tehran Stock Exchange". Mediterranean Journal of Social Sciences Rome-Italia, 7(4) S1, July, 208-214.

Appiah, Kingsley Oppoku dan Joshua Abor. 2009. "Predicting Corporate Failure: some Empirical Evidence from the UK", Benchmarking: An International Journal, 16(3), 432-444.

Appiah, Kingsley Opoku, Amon Chizema, dan Joseph Arthur. 2015. "Predicting Corporate Failure: a Systemic Literature Review of Methodological Issues". International Journal of Law and Management, 57(5).

Beaver, William H., Maureen F. McNicholas, dan J. W. Rhie. 2005. "Have Financial Statements become Less Informative? Evidence from the Ability of Financial Ratios to Predict Bankruptcy". Review of Accounting Studies, 10(1),. 93-122.

Beaver, William H., Maria Correia, dan Maureen F, McNichols. 2010. "Financial Statement Analysis and the Prediction of Financial Distress". Foundation and Trends® in Accounting, 5(2), 99-173.

Bellovary, Jodi, Don Giacomino, Michael Akers. 2007. "A Review of Bankruptcy Prediction Studies: 1930Present". Journal of Financial Education, 33, 1-42.

Chitnomrath, Thanida, Robert Evans, Theo Christoper. 2011. "Corporate Governance and Post-bankruptcy Reorganisation Performance: Evidence from Thailand", Asian Review of Accounting, 19 (1), 50-67,

Cultera, Loredana dan Xavier Bredart. 2016. "Bankruptcy Prediction: the Case of Belgian SMEs". Review of Accounting and Finance. 15 (1), 101-119 
Cybinski, Patti. 2001. "Description, Explanation, Prediction - the Evolution of Bankruptcy Studies?". Managerial Finance, 27(4), 29-44.

Cybinski, Patti dan Carolyn Windsor. 2005. "The Efficacy of Auditors' Going-concerns Opinions Compared with a Temporal and an Atemporal Bankruptcy Risk Model: Analysing US Trade and Service Industry Failures 1974-1988". Pacific Accounting Review, 17(1), 3-36.

Feldmann, Dorothy dan William J. Read. 2013. "Going-concern Audit Opinions for Bankrupt Companies - Impact of Credit Rating". Managerial Auditing Journal, 28(4), 345-363.

Foster, Benjamin P. dan Josef Zurada. 2013. "Loan Defaults and Hazard Models for Bankcruptcy Prediction". Managerial Auditing Journal, 28(6), 516-541.

Grice, J.S. dan R.W. Ingram. 2001. "Tests of The Generalizability of Altman's Bankruptcy Prediction Model". Journal of Business Research, 54(1), 53-61.

Hopwood, W., J.C. McKeown, dan J.F. Mutchler. 1994. "A Reexamination of Auditor versus Model Accuracy within the Context of The Going-concern Opinion Decision". Contemporary Accounting Research, 10(2), 409-431.

Hwang, Ruey-Ching, Huimin Chung, Jiun-Yi Ku. 2013. "Predicting Recurrent Financial Distresses with Autocorrelation Structure: An Empirical Analysis from an Emerging Market". Journal of Financial Service Research, 43. 321 - 341.

Ikatan Akuntan Indonesia. 2004. Media Akuntansi, Edisi 40.

Ikatan Akuntan Indonesia. 2015. "Akuntan Indonesia Bersatu Hadapi Krisis Global, Akuntan Indonesia". Akuntan Indonesia, Agustus - September 2015.

Kuruppu, Nirosh, Fawzi Laswad, dan Peter Oyelere. 2003. "The Efficacy of Liquidation and Bankruptcy Prediction Models for Assesing Going Concern". Management Auditing Journal, 18(6/7), 577-590.

LeClere, Marc J. 2006. "Bankruptcy Studies and Ad Hoc Variable Selection: a Canonical Correlation Analysis". Review of Accounting and Finance, 5(4), 410-422.

Partington, Graham, Philip Russel, Max Stevenson, Violet Torbey. 2001. "Predicting Return Outcomes to Shareholders from Companies Entering Chapter 11 Bankruptcy". Managerial Finance, 27(4), 78-96.

Ohlson, J.A. (1980), "Financial Ratios and the Probabilistic Prediction of Bankruptcy", Journal of Accounting Research, 18(1), 109-131.

Salehi, Mahdi dan Mahmoud Mousavi Shiri. 2016. "Different Bankruptcy Prediction Patterns in an Emerging Economy: Iranian Evidence", International Journal of Law and Management, 58(3), 258-280,

Smith, Malcolm dan Dah-Kwei Liou. 2007. "Industrial Sector and Financial Distress". Managerial Auditing Journal, 22(4), 376-391.

Stanley, Jonathan, F. Todd De Zoort, dan Gary Taylor. 2009. "The Association between Insider Trading Surrounding Going Concern Audit Opinions and Future Bankcruptcy". Managerial Auditing Journal, 24(3), 290-312.

Sun, Jie, Hui Li,Qing Hua Huang, dan Kai-Yu He. 2014. "Predicting Financial Distress and Corporate Failure: a Review from the State-of-the Art Definitions, Modeling, Sampling, and Featuring Approaches". KnowledgeBased Systems 57, 41-56.

Watts, Ross L. dan Jerold L. Zimmerman. 1986. Positive Accounting Theory. New Jersey: Prentice-Hall.

Wolk, Harry I., James I. Dodd, dan John J. Rozycki. 2017. Accounting Theory: Conceptual Issues in a Political and Economic Environment, Ninth Edition. Los Angeles: SAGE Publication Inc.

Zmijewski, M.E. 1984. "Methodological Issues Related to the Estimation of Financial Distress Prediction Models/discussion", A Journal of Accounting Research, 22, Supplement, pp. 59-82. 